\title{
Rational Behavior of Employees Driven by Economic Interests
}

\author{
Irina Bocharova \\ State University - Education-Science-Production Complex \\ Email: i-bocharova@yandex.ru
}

\section{Doi:10.5901/mjss.2014.v5n20p671}

\begin{abstract}
In existing theories of human behavior the concept of self-interest is of immense significance. Debates over the self-interest in the economic theory have grown in scale as models of individual economic behavior within the rational choice theory and economic theory of welfare gained currency. The aim of the study is to explore modern concepts of self-interest and reveal trends in development of the self-interest theory as based on identification of preconditions, factors and criteria of rational behavior in hired personnel within an organization which is driven by the self-interest. The methods of analysis and synthesis, induction and deduction, analogy were employed in the study. Findings of the study: boundedly rational nature of the selfinterest was revealed in the organization personnel; prescriptive nature of personal interest impact on behavior was revealed in the organization personnel; methodological aspects of self-interest identification in hired personnel were implemented based on analysis of their conscious rational behavior within the organization; practical prerequisites for economic behavior in personnel were identified.
\end{abstract}

Keywords: self-interest; economic interest; employee; norm of interest; rationality; bounded rationality;

\section{Introduction}

The economic interest concept is prevalent in the existing theories of employee behaviour. The assumption of economic interest is not a stand-alone theoretical concept; rather, it is a collectively shared cultural ideology. Classical interpretation of economic interest requires that the interests that encourage employees be economic in nature.

\section{Literature Review, Theoretical Background}

\subsection{Employee acts in accordance with the economic interest concept}

Various studies suggest that an employee is acting in accordance with the concept of economic interest (Miller and Ratner, 1996; Sampson, 1983; Wallach and Wallach, 1983). The attitude and behaviour of employees are influenced by both monetary incentives and other personal motives. Economic interest has a certain influence on the formation of the employee attitude and behaviour.

Various motives of the employee behaviour are shaped both on the basis of personal experience and through external regulations.

\subsection{External regulations}

Various studies highlight the fundamental questions about the nature of human activity: "Science creates the concepts and methods of understanding the world and our place in it which has a huge impact on how we think and act" (Schwartz, 1997). Collective understandings which reveal what motivates people (via descriptive theories) and what means should be used to motivate them (as prescriptive theories) are of great importance. Collective understandings take the form of direct and indirect regulations. Requirements of the power of economic interest tend to be long-term. Numerous calls to the pursuit of economic interest emphasize the assumption that the above motive is strong and influential. Calls to the pursuit of economic interest directly indicate the means used to achieve this goal, and indirectly appeal to the prudence and appropriateness of pursuing economic interest (Miller, 1999; Bocharova, 2005; Bocharova, 2007).

External indication on what appears employee's economic interest may promote their perception of the above interest. The commitment of employees to their economic interest grows once they identify it. However, it can also promote the perception of the norm of economic interest. The result is that the actions of an individual driven by the 
economic interest can be explained both by the economic interest itself, as well as the social standard of the economic interest.

\subsection{Individual experience.}

Some studies indicate that the employees' daily activities may exceed the actual influence of the economic interest.

Self-asserting causes of the economic interest assumptions. It is generally acknowledged that any scientific theory may well become self-sufficient through forming self-reflection and self-actualization. Where the assumption of the economic interest is concerned, the above is all the more true since the assumption of individually interested employees is the key element in many influential theories of human behaviour, including evolutionary biology, behaviourism, psychoanalytic theory, etc. The self-sufficient nature of the economic interest assumption has been the subject of many studies (Schwartz, 1997).

The economic interest assumption promotes its own validation for the following reasons (Miller, 1999):

1. In individualistic cultures, social institutions are established to reflect their function that people tend to pursue their own economic interests.

2. Individualistic cultures generate social standards that encourage people to follow their material economic interests, rather than to pursue their own principles and passions, regardless of whether they are noble or ignoble in nature. This means that people act as if they were strongly motivated by their material economic interest, because scientific theories and collective understandings formed on their basis convince people that the way they act is the most natural one. Some researchers note that people regard their own interest as a natural law to be adhered to as they believe that it should not be violated. Stringent requirements discussed in these models provoked certain criticism. According to some researchers, the economic interest assumption is characterized by a certain level ambition, because the ideology of economic interest works as a powerful selfassertive force. The critics of the economic interest concept believe that the general nature of the economic interest assumption may be quite misleading for individuals. They believe that more acceptable is the assumption that the behaviour of individuals should be focused on the motives of the economic behaviour such as social involvement, self-expression, commitments, and fairness.

The proponents of the theory of rational choice, based on the assumption of economic interest, either reject the arguments presented by critics by regarding them as isolated examples, and, therefore, characterize them as mere exceptions to the rule, or explain them by what is called the rational (i.e. interested) attitude.

\subsection{The norm of economic interest}

In countries with a predominance of individualistic ideology, the so-called the norm of economic interest has become widely spread. It influences the actions and decisions of employees, as well as impacts the arguments they use to explain them. In particular, it helps ensure that employees act as if they cared about their material economic interest more than it actually is. As a result, individuals often act only in accordance with the economic interests they perceive, because they believe that acting otherwise is violating stringent descriptive and prescriptive regulations.

The norm of interest requires that people should pursue their economic interests. The conclusion that the material economic interest is powerful enough may to some extent suggest how rigid the social standards are, rather than how strong are the innate aptitudes of employees that are shaped historically and culturally. The explanation of the interested behaviour for the purpose of the assumption of universality and inevitability of the economic interest, rather than its formation historically and culturally, helps ensure that the pursuit of the economic interest is appropriate and rational. The result is the formation of a positive feedback: the stronger the economic interest standard, the more grounds there are for the theory of the economic interest, which, in turn, enhances the norm of interest (Schwartz, 1997).

\section{Results and Discussion}

Prerequisites, factors and criteria of employee motivation. There are many factors that impact the behaviour of employees in a company. There are factors that employees are aware of, and there are some they are not; there some factors that are rational in nature, driven by economic interests; and, still, there certain factors that are irrational (Fig. 1).

An employee whose behaviour is based on conscious rational choice (Fig.1, quadrant I) is the company's most valuable asset. 


\begin{tabular}{|c|c|c|}
\hline 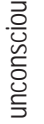 & IV & III \\
\hline 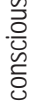 & 1 & ॥ \\
\hline & rational & irration \\
\hline
\end{tabular}

Figure 1. Matrix of the types of factors affecting employee motivation

Employee motivation can be explained by a set of prerequisites and criteria of their behaviour. The analysis of the conscious and rational prerequisites of the employee behaviour driven by their economic interests is a part of the research subject. This type of behaviour, in the first place, may be evaluated by the necessity to achieve the main goal of a company (i.e. the company's mission). Prerequisites for such behaviour of employees incorporate two types of elements: values and practical assets. Values are associated with the objectives of an employee; practical assets are associated with the possible means to achieve them (Fig. 2).

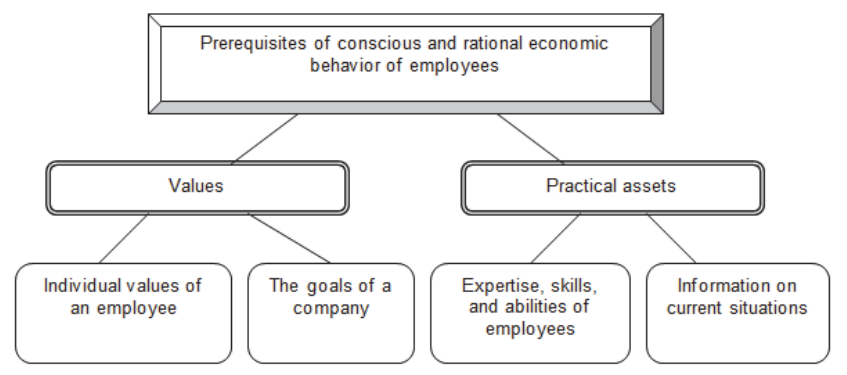

Figure 2 Prerequisites of economic behaviour of employees

However, the discrimination between these elements is rather arbitrary as each value may comprise certain practical assets. Thus, individual goals generally represent a means of achieving the more remote strategic objectives.

Basic value prerequisites for employee motivation. The basic value prerequisites of the employee conscious rational behaviour driven by personal economic interests are individual and company values.

\subsection{Individual values of an employee}

Individual values are the major factor that governs the formation of conscious rational behaviour driven by the economic interests of employees. Workers constantly assess their actions, both consciously and unconsciously, by comparing them with their economic interests. In some cases, the individual values of employees may run counter to the economic interests of a company. In this context, the company's management should seek to create the necessary incentives for employees to encourage them to consider to the interests of the company.

Some of these incentives include (Barnard, 1938):

- economic drivers;

- awards, distinctions, gaining prestige and influence;

- physical conditions of work;

- pride in personal skills;

- favourable relationships with colleagues;

- compliance with behaviour patterns adopted by the company;

- sense of being a part of important events. 


\subsection{Company values}

Insofar as an employee performs his duties in accordance with the major objectives of the company's activities, the values and economic interests of the company also influence the economic behaviour of employees. Employees will act in line with the major objectives of a given company.

\subsection{The ratio of individual and company values}

Bounded rational behaviour of employees, which is driven by economic interests. The rational behaviour driven by economic interests and intangible benefits is vital in assessing the behaviour of employees. Company's management decisions with regard to employees can only be implemented if the employees' decisions are slaved to the management decisions (Simon, Smithburg, and Thompson, 1950). However, the decisions of employees are not fully defined by their free will. Economic interests of employees are to some extent derived from a company's objectives. Being a part of a particular company involves adaptation, change of behaviour of an individual employee by changing the actual prerequisites for his/her behaviour (Davis, 1996). Employee behaviour is rational from the perspective of a company if it does not run counter to the economic interests of the company.

Being a part of a company imposes certain restrictions on the behaviour of an employee, thus making his/her actions bounded rational (with regard to the objectives of the company). This pattern of behaviour is characteristic both of subordinates and superiors.

Bounded rationality is a focused, predictable form of the employee behaviour (Simon, Smithburg, Thompson, 1950). Rational analysis of the employee behaviour is a calculated process of his/her mind based on the selection of the desired values within the company goals. Nevertheless, adaptation of the employee behaviour to the company's goals does not involve consent and simple obedience to administrative decisions of a company. It involves the perception of organizational problems by employees in the form of discussion, procedures for constructing the company's objectives, assessment of the final recipients of the benefits derived from achieving these goals, etc.

Practical implications of the employee motivation.

Practical implications of the employee motivation in a company can include two types of elements:

1) Expertise, skills, and abilities of employees;

2) supplementary information about current situations needed for production decisions.

Methodologically, it is important to distinguish between the above two elements. Prerequisites of the first type are acquired in the course of training and hands-on experience. Prerequisites of the second type is information about the unforeseen events in the current activities of employees, which has the nature of the uncertainty of internal and external factors.

Identification of the economic interests of employees that have a direct impact on their economic behaviour in the organization based on the implementation of the methodology of "incentive-contribution" (Barnard, 1938; March and Simon, 1958; Personnel management, 1997; Rymanov, 2014). It aims to identify the reasons for employment in a particular company, and assess an employee for compliance with the company management expectations. According to this methodology, a company should create the necessary incentives for employees (wages, more challenge for one's abilities, etc.). In response, the company's employees have to "make" the necessary contribution into the company's activities (in the form of performance). The key condition for the functioning of this methodological approach is to ensure equilibrium between "incentive-contribution." Employees remain committed to their jobs within a company, based on individual evaluation criteria, as long as the incentives provided by the company correspond to (or exceed) the contributions of employees.

A company turns the contributions made by employees into the incentives. In this case, the company will be in good standing in the field if it can - while effectively utilizing employee's contributions - provide a set of incentives to employees in such quantity and quality that they do not change their attitudes to their duties.

\section{Concluding Remarks}

Economic interests that motivate employees are economic in nature. The behaviour and attitude of employees are affected both by pecuniary and other personal motives. The motive of the economic interest pursuit is strong and influential. The pursuit of economic interest becomes more intense once it has been identified and can lead to the perception of the economic interest standard, encouraging individuals to pursue their economic interests. Various motives of the employee behaviour are shaped both on the basis of personal experience and through external regulations. Acting 
in accordance with the perceived economic interests, individuals believe that to do otherwise would be to violate the existing descriptive and prescriptive rules. The economic interest is a significant force stimulating the activities of the employees.

Industrial and economic democracy in the workplace helps implement the economic interests to a fuller extent.

A conscious and rational behaviour of an employee, which is based on the value and practical prerequisites, is most vital for a company. The "incentive-contribution" methodology can be an efficient means of impacting employee motivation, thus helping them implement their economic interests.

\section{References}

Miller, D. T. and Ratner, R. K. (1996). The power of the myth of self-interest. In L. Montada and M. J. Lerner (Eds.), Current societal issues in justice (pp. 25-48). New York: Plenum.

Sampson, E. E. (1983). Justice and the critique of pure psychology, New York: Plenum.

Wallach, M. A. and Wallach, L. W., 1983. Psychology's Sanction for Selfishness: The Error of Egoism in Theory and Therapy. New York: Freeman.

Schwartz, B. (1997). Psychology, idea technology, and ideology. Psychological Science, 8(1): 21-27.

Miller, D.T. (1999). The Norm of Self-Interest. American Psychologist, 54(12): 1053-1060.

Bocharova, I., 2005. Institute for representing economic interests of employees. Labour and social relations, 1: 29-43.

Bocharova, I. (2007). Economic interests in a firm. Lomonosov Moscow University, Maks-press.

Rymanov, A. (2014). Moscow International Financial Centre Federal Government Outlays. World Applied Sciences Journal, 30 (6): 706709 .

Barnard, C.I. (1938). The Functions of the Executive. Cambridge, MA: Harvard University Press.

Simon, H., Smithburg, D., Thompson, V. (1950). Public Administration. New York: Alfred Knopf.

Davis, C. (1996). The Administrative rational model and public organization theory, Administration and Society, 28(1).

March, J.G., Simon H.A. (1958). Organizations. - New York, Wiley.

Personnel management in a social market economy, 1997, Eds. R.Marr and H. Schmidt. Lomonosov Moscow University.

Rymanov, A. (2014). Corporate Financial Stability and its Liquidity: How Strong is the Connection?. Middle-East Journal of Scientific Research, 20 (9): 1103-1106. 